\title{
Effect of Mother Baby Care (MBC) Package with the Palembang Cultural Approach Adaptation to Physic and Psychological Period Post Partum
}

\author{
$1^{\text {st Jawiah }}$ \\ Nursing Department \\ Politeknik Kesehatan Kemenkes Palembang \\ Palembang, Indonesia \\ jawiah.cikamin@yahoo.com
}

\author{
$2^{\text {nd }}$ Devi Mediarti \\ Nursing Department \\ Polteknik Kesehatan Kemenkes Palembang \\ Palembang, Indonesia \\ devi_mediarti@gmail.com
}

\author{
$3^{\text {rd }}$ Rosnani \\ Nursing Department \\ Polteknik Kesehatan Kemenkes Palembang \\ Palembang, Indonesia \\ rosnani_usm@yahoo.com
}

Corresponding author: jawiah.cikamin@yahoo.com

\begin{abstract}
Self-reliance can be done by building a empowerment woman and child-directed quality of life and the role of women through the success of post partum mothers in mer awat herself and her baby. Pemulangan early from hospitals require assistance care at home with nursing care method Mother Baby Care (MBC) with Palembang cultural approach. The purpose of this study to assess the effect of packet MBC with a cultural approach Palembang to physical and psychological adaptation mom post partum. The methode used Quasi-Eksperimental pretest-posttest with Controllergroup . Sampling using purposive sampling, with 30 respondents each group. Bivariate data analiysis used two different mean dependent samples paired t-test, Wilcoxon and Mann Whithney test. Diperoleh $h$ acyl research there is not a difference sigi ni fican physical adaptations post partum mothers before and after the intervention of the intervention group. $p$ value $=0.000, t$ idak ada differences in physical adaptations mother postpartum seb forgetting and after the intervention in the control group $p$ value $=0.397$, there are significant differencec in adaptation of psychological maternal postpartum before and after the intervention group intervensi $p$ value $=0.000, t$ There was no difference in psychological adaptation of post partum mothers both before and after the intervention in the control group. $p \quad$ value $=\mathbf{0 . 1 1 4}$. Results of multivariate concluded that age (p value: 0.006 ) and family support ( $p$ value: 0,036 ) Mother adaptation influence post partum after getting a care package Mother Baby Care (MBC) with approach Palembang culture.
\end{abstract}

Keywords: Mother Baby Ca re (MBC), Adaptation, Post Partum.

\section{INTRODUCTION}

Program Sustainable Development Goals (SDGs) 2015- 2030 in the field of health one of them to the family has plans to $\mathrm{u}$ marsh empower all women and girls to succeed. This vision is in line with the Ministry of Health's vision of the realization of a healthy and independent and just society. Melan cited the degree of public health, through community empowerment, including the private sector.

The term of community independence can be done by building the empowerment of women and children aimed at improving the quality of life and the role of women, welfare, and protecting children in various fields of development; decrease in the number of acts of violence, exploitation, and discrimination against women and children; and strengthening institutional and gender mainstreaming networks and children at the national and regional levels, including the availability of data and gender statistics (RI Law No.17, 2007). The efforts of the community in general are inseparable from the culture adopted in overcoming the health problems that exist in the community.

Cultural practices are carried out by the community more when mothers are treated at home, especially in mothers who are postpartum. With the development of the concept of postpartum care (postpartum) that the early discharge of patients, this causes the mother's home care period is longer than before. Preparation for early repatriation is not sufficient to equip the skills of 
mothers and families in dealing with the post partum period. This makes it more possible to adopt local customs, traditions and culture through their care. Cultural practices that are not appropriate to health and only focus on the physical problems of the mother, often make the conditions of maternal health not maintained until the end of their reproduction. This is shown on the Maternal Mortality Rate (MMR) in Indonesia is still far from the target of MDGs by 2015. MMR in Indonesia in 2015 is 305 per 100,000 live births, with a direct cause and not directly.

Until now, the nursing care at home (home care ) in women during post partum not arranged with good nursing care postpartum mother to the mother and baby at home (home care) need to be prepared before the mothers are discharged from hospital. Namun, repatriation early mempengaruhi success of treatment post partum mothers, this is because berku overall lack of opportunity to be given health education, observation during breastfeeding, and instruksi practically correct breastfeeding techniques[1] . Post partum mother care at home is strongly influenced by family and community support. Praktik- cultural practices carried out in the community is opposed to the treatment of maternal health.

Impact cultural practice of nursing mothers and their babies can be a serious problem to the physical and psychological changes post partum. Socio-economic factors of the family, response to stress, and culture are key factors that influence health [2]. A care approach that can be taken to mothers such as Mother Baby Car e (MBC) in short community culture. $\mathrm{MBC}$ is a Mother and Baby Care which is also known as mutual mutual care (dyad care), focusing on physical, psychological, social and economic nursing . Nurses assess individuals as they function in the family. Communication between health professions and parents is becoming more integrated, reducing the potential for mistakes and confusion. Nurses need to provide an educational model for mothers and families through learning and teaching processes so that a physiological and psychosocial condition is achieved for the baby by taking into account social and cultural factors in its interventions.

Research on treatment to meet the needs of holistik mother during the post partum period in the context of the culture of South Sumatra has not been widely studied. Therefore, it is felt necessary to conduct research into the use of $t$ ) in the context of South Sumatra's culture of physical and psychological changes during post partum.

\section{RESEARCH METHODOLOGY}

Research conducted on July 9 - 31 October 2018 using the Quasi Experimental Pretest-Posttest with control group research. Population are mother post partum domiciled in the city of Palembang. The technique of taking sampel using purpossif sampling with the inclusion criteria : $\mathrm{b}$ ailable for examination, Post partum days 1-40 days, age of mothers are 20- 35 years, not impaired mental, and mother original Palembang, who lived in the city of Palembang. Samples research was 60 respondents 30 respondents kelompok interventions, and 30 group control.

Univariate analysis of the frequency distribution of a change in the physical and psychological post partum mothers in both groups. Analysis bivariate using test Wilcoxon, dependent pairet test samples ttest, and test Mann-Whitney, while the analysis of multivariate used ad ne test MANOVA.

\section{RESULTS}

\section{A. Sample Characteristics}

Table 1. Frequency Distribution of Respondents by Age of Mother Post $\mathbf{t}$ Partum in Ilir Barat II Palembang

\begin{tabular}{lcccc}
\hline Variable & $\begin{array}{c}\text { The } \\
\text { mean }\end{array}$ & Median & $\begin{array}{c}\text { Stand ar } \\
\text { Deviation }\end{array}$ & Min- Max \\
\hline $\begin{array}{c}\text { Age } \\
\text { (years) }\end{array}$ & 29.53 & 30 & 4,848 & $24-37$ \\
\hline
\end{tabular}

Table 2. Frequency Distribution of Respondents by Biodata Mrs. Post Partum In the intervention group in Ilir Barat IIPalembang

\begin{tabular}{lccc}
\hline \multicolumn{1}{c}{ Variable } & Frequency & $\begin{array}{c}\text { Percentage } \\
(\boldsymbol{\%})\end{array}$ & amount \\
\hline Parity: & 17 & $\mathbf{5 6 . 7}$ & 30 \\
- Multigravida & 13 & $\mathbf{4 3 . 3}$ & \\
- Primigravida & 22 & $\mathbf{7 3 . 3}$ & 30 \\
\hline Education: & 8 & $\mathbf{2 6 . 7}$ & \\
- Height (PT) & & & \\
- Low & & & \\
$\quad$ elementary- & & & \\
$\quad$ high school) & 20 & $\mathbf{6 6 . 7}$ & \\
\hline Profession : & 10 & $\mathbf{3 3 . 3}$ & \\
- working & & & \\
- Housewife & 10 & $\mathbf{3 3 . 3}$ & \\
\hline Family support : & 14 & $\mathbf{4 6 . 7}$ & \\
- There isn't any & 6 & $\mathbf{2 0 . 0}$ & \\
- Sometimes & & & \\
- Always supportive & & & \\
\hline
\end{tabular}


According to the table 5.2 in mind sebagian mothers post partum multigravida $\mathrm{n}=17(56.7 \%)$, college education $\mathrm{n}=22$ respondents $(73.3 \%)$, work 20 responden $(66.7 \%)$ and the support 20 respondents $(66.7 \%)$.

\section{B. Analysis of Physical and Physicological Differences Before and After Intervention} $C$.

Table 3. Distribution of Average Adapted Physical d an PSIK the biological mother post partum Pre-Post Intervention on K Secondly Kelompok in Ilir Barat II Palembang

\begin{tabular}{ccc}
\hline Group & $\begin{array}{l}\text { Physical } \\
\text { Adaptation }\end{array}$ & $\begin{array}{c}\text { Psychological } \\
\text { Adaptation }\end{array}$ \\
\hline Intervention & 0,000 & 0,000 \\
Non Intervention & .397 & 0,114 \\
\hline
\end{tabular}

From the table it is known that there is a difference significant physical adaptations post partum mothers before and after given interven the $\mathrm{p}$ value $=0,000$ at kelompok intervention, while the co ntrol $\mathrm{p}$ value $=$ 0.397 dition mpulkan no difference in maternal postpartum physical adaptation before and after the intervensi.

The results of the analysis of the adaptation of psychological obtained $\mathrm{p}$ value $=0.000$, meaning that there is a difference signifi $\mathrm{k}$ an adaptation of the psychological mother po st partum before and after the intervention in the intervention group, whereas the control group there was no difference in the adaptation of psychological mother postpartum both before and after the intervention with $\mathrm{p}$ value $=0.114$.

Table 4. Distribution of Average Adaptation Mrs. Post Partum Se has not Given intervention on Both Kelpompok in Ilir Barat II Palembang

\begin{tabular}{lccc}
\hline \multicolumn{1}{c}{ c } & $\begin{array}{c}\text { The } \\
\text { mean }\end{array}$ & $\begin{array}{c}\text { Elementary } \\
\text { school }\end{array}$ & P value \\
\hline Physical Adaptation & 23.63 & 7.59 & .137 \\
Psychological_Adaptation & 15.70 & 3,748 & 0.141 \\
\hline
\end{tabular}

Popularity hasil pre-test is obtained $\mathrm{p}$ value $=0.137$, then concluded there was no difference in physical adaptation maternal postpartum before the given module and the treatment of MBC between a group intervention and control groups then adapatsi psychological obtained $\mathrm{p}$ value $=0.141$, then concluded there was no difference in the adaptation of psychological post partum mothers before administration modules and maintenance MBC between the intervention and kelompok control.
Table 5. Average Distribution of Adaptation of Post Partum Mothers After Granting Interventions in both groups in Ilir Barat II Palembang

\begin{tabular}{lccc}
\multicolumn{1}{c}{ Variable } & $\begin{array}{c}\text { The } \\
\text { mean }\end{array}$ & $\begin{array}{c}\text { Elementary } \\
\text { school }\end{array}$ & $\begin{array}{c}\text { P } \\
\text { value }\end{array}$ \\
\hline Physical Adaptation & 26.58 & 7,922 & 0.614 \\
$\begin{array}{l}\text { Psychological } \\
\text { Adaptation }\end{array}$ & 17.65 & 2,510 & 0,000 \\
\hline
\end{tabular}

From the table above, $\mathrm{p}$ value $=0.614$ is obtained, so it can be concluded that there is no difference in physical adaptation of post partum mothers after being given modules and MBC care between the intervention and control groups. Adapatsi psychological obtained $\mathrm{p}$ value $=0,000$, it can be concluded terdapat difference adaptation postpartum mothers psychologically after a given module and $\mathrm{MBC}$ treatment between the intervention and clogs pok control.

\section{Multivariate Analysis}

Table 6. Results of Multivariate Analysis of Factors Mempen garuhi Adaptation Physical and Psychological Capital Post Partum After Provided intervention in Ilir Barat II Palembang

\begin{tabular}{|c|c|c|c|}
\hline & Mother's Adaptation & $\mathbf{F}$ & P value \\
\hline Parity & Physical Adaptation & 2,745 & .111 \\
\hline \multirow{3}{*}{ Age } & $\begin{array}{l}\text { Logical Psycho } \\
\text { Adaptation }\end{array}$ & .149 & .703 \\
\hline & Physical Adaptation & 8,938 & 0.006 \\
\hline & $\begin{array}{l}\text { Psychological } \\
\text { Adaptation }\end{array}$ & 0.122 & 0.730 \\
\hline Famil & Physical Adaptation & 4,952 & 0.036 \\
\hline $\begin{array}{l}\text { y } \\
\text { supp } \\
\text { ort }\end{array}$ & $\begin{array}{l}\text { Psychological } \\
\text { Adaptation }\end{array}$ & .101 & .753 \\
\hline \multirow[t]{2}{*}{ Peker jaan } & Physical Adaptation & 2,528 & 0.125 \\
\hline & $\begin{array}{l}\text { Psychological } \\
\text { Adaptation }\end{array}$ & 0.786 & .384 \\
\hline \multirow[t]{2}{*}{ Education } & Adapta the Physical & 0.089 & 0.768 \\
\hline & $\begin{array}{l}\text { Psychological } \\
\text { Adaptation }\end{array}$ & 2,567 & 0.122 \\
\hline
\end{tabular}

Based on the table III.1 known that the age factor $\mathrm{p}$ value of 0.006 and family support to adaptation physically 0.036 and concluded that keduanya mempengaruhi adaptation post partum mother after getting intervention. Being right for parity factor, job and education obtainedhacyl $p$ value > 0.05, which means there is no effect after DIBE ri intervention.

\section{DISCUSSIONS}

The complaints of the post partum mothers found in this study were weakness, fatigue, sleepiness, body discomfort, dizziness, cramps, mules during breastfeeding, lots of blood coming out, breast pain and 
peri neum pain. This is similar to the study by [3]. Psychological complaints can occur in mothers who experience physical problems and can even experience depression when not recognized and not treated immediately [4] [5]. The results of this study indicate the ability of mothers to resolve post-partum health problems is strongly influenced by the support system of their husbands, parents or the community. Post partum mothers who get good support from their husbands or families will find it easier to adjust. Psychologically the mother does not feel alone when experiencing health problems. The results of research in British Columbia, of 396 mothers of periods one, four, and eight weeks post partum, obtained the results of a positive correlated partner support with social support [6]. This is consistent with the results of research that the needs of mothers are very important and need to be supported by husbands, mother-in-law, village midwives, cadres and village leaders as well as the existence of a cultural role [7]. Post partum mother's needs are the needs of her support and care. Mother's efforts to solve breastfeeding and perineal pain problems by doing traditional practices. The practice that mothers do when experiencing breastfeeding problems is by drinking herbal medicine and eating vegetables. The results are consistent with the mothers in the village Kajoran South Klaten Indonesia, mer habits eka clicking the consumption of herbs while nursing [8]. Research [9], two factors masala $h$ breastfeeding and lack of exclusive breastfeeding in Nicaragua is feeding prior to lactation and maternal perceptions of the baby to be large at birth. Most research shows cultural support for breastfeeding, although most traditional societies delay breastfeeding because colostrum is considered 'dirty' [1]. For perineal pain, the mother sits on a heated brick. This cultural practice obtained from mother - in -law stems from habits taught by grandmothers or their predecessors. Cultural practices are carried out with herbs and spices that can be made by yourself, bought or received treatment from a massage shaman. Unlike the case with research [10], for problems such as urinary tract infection (UTI) pene Litian in vitro have shown the effects of fruit Rosa Canina in preventing the growth of Escherichia coli .

Research conducted by Sari, Husaini, \& Ilmi (2017) [11], in which there are restrictions on maternal and childbirth mothers are grouped into 3 categories namely behavioral, food and beverage restrictions. Various post partum period practices were obtained in Asia, North America and Africa, there is a strong cultural understanding of the power of healing through daily food [1]. One of the indigenous groups in the Malaysia Peninsula, had their own taboo and avoidance of special foods during the postpartum period. Dietary restrictions begin immediately after delivery for up to one month [12].

The traditional intervention carried out by the Palembang Indonesian people in this study is a steam bath in order to carry out body treatments. In the people of Aceh Indonesia, body care is carried out by means of a post partum mother undergoing a sale, which is sleeping on a divan made of wood or bamboo sticks that are cracked and under the couch is placed a stove filled with hot charcoal. The trauma is considered to accelerate the process of deflating the stomach and uterus, closing the genitals, and warming the body. The dukun beranak in Kelurahan Majene, handles post partum mothers based on the knowledge he has gained from dreams. Mother must lift water from the well to the house to restore physical strength [13].

The behaviour post partum mothers to overcome their health problems according to the results of the study [11], in the Banjar tribe are grouped into 3 categories in obtaining treatment, namely from village shamans, customs and from health workers. Health workforce activities according to [14] an evaluation of the Mom to Mom (M2M) program can help women overcome the first year of care through visits that have the capacity to overcome challenges in the post partum period among women from diverse cultures. Ideally these interventions should develop behaviors that support recognized cultural life such as breastfeeding, post partum counseling, rest and recovery. Then by modifying potentially harmful aspects of other cultural practices during the perinatal period [1]. Unreachable and inadequate program, related to a culture of mistrust and suspicion, mothers from Black and Minority Ethnic (BME) about perinatal health services [15].

In the context of migration, immigrant mothers are powerless to understand the meaning of the post partum sexual life [10] community neonatal interventions must be adapted to the population of existing practice and knowledge. In the population studied, traditional practices in the partum period are no longer common. Multidimensional assessment of acculturation can prove useful in better adjusting future breastfeeding promotion interventions[16]. There are several methods traditional in the whole world yang beneficial and harmful to both mother and baby [17].

Cultural practices undertaken by mothers during post partum require help from health workers to bridge the needs of mothers. Like the results of this study, the expectation of mothers towards self care requires involvement of husband, family and health workers. The form of support that mothers need in the form of understanding, accompanied by their husbands, parents and health workers in providing their care needs [18].

Culturally competent health care interventions must be developed from the earliest post partum period. As a promotion of social support and self-efficacy care for new mothers. Research on 68 mothers who received social support and self- efficacy care. It was found that, perceived social support and self- efficacy care decreased at the beginning of post partum. Parenting 
self-efficacy increased from six weeks to three months post partum. Social support was felt to be positively correlated with self-efficacy caregiving [19].

Health workers need to provide interventions for postpartum mothers with health education packages [20]. This is because the advice of health care workers and access to available health services bring better conditions after giving birth [21].

\section{CONCLUSION}

There were significant differences in the physical adaptation of post partum mothers before and after the intervention in the intervention group. $\mathrm{P}$ value $=$ 0,000 . There is no difference in physical adaptation postpartum mothers before and after the intervention in the control group $\mathrm{p}$ value $=0.397$, a significant difference in psychological adaptation of post partum mothers before and after the intervention in the intervention group $\mathrm{p}$ value $=0,000$, but no difference in the adaptation of psycho logical postpartum mothers both before and after the intervention in the control group $\mathrm{p}$ value $=0,114$, but there is no difference in maternal postpartum physical adaptation between the group given module and MBC treatment with only diberika $\mathrm{n}$ MBC module $\mathrm{p}$ value $=0.137$. There is no difference in psychological adaptation of post partum mothers among the group given mod ul and treatment of MBC with $\mathrm{MBC}$ who were given module $\mathrm{p}$ valu $\mathrm{e}=0.141$, no difference in maternal post partum physical adaptations after $\mathrm{d}$ iberikan modules and MBC treatment between the intervention group and the control group $p$ value $=0,614$, differences in a daptasi psychological postpartum mother after a given module and $\mathrm{MBC}$ treatment between the intervention group and the control group $\mathrm{p}$ value $=0,000$, and factor age and family support for physical adaptation obtained $p$ value $=0.05$ ie 0.006 for age and 0.036 for family support. It can be concluded both of them affect the adaptation of post partum mothers after getting intervention. Factors parity, employment and education results obtained $\mathrm{p}$ value $>0.05$, meaning that there is no influence of these factors on the physical and psychological adaptation of post partum mothers after obtaining intervention .

\section{REFERENCES}

[1] Raman S, Nicholls R, Ritchie J, Razee H, Shafiee S. How natural is the supernatural? Synthesis of the qualitative literature from low and middle income countries on cultural practices and traditional beliefs influencing the perinatal period. Midwifery 2016;39:87-97. https://doi.org/10.1016/j.midw.2016.05.005.

[2] Lowdermilk, Perry, Cashion. Buku Ajar Keperawatan
Maternitas. Jakarta: EGC; 2013.

[3] Woolhouse H, Gartland D, Perlen S, Donath S, Brown SJ. Physical health after childbirth and maternal depression in the first 12 months post partum: Results of an Australian nulliparous pregnancy cohort study. Midwifery 2014;30:378-84. https://doi.org/10.1016/j.midw.2013.03.006.

[4] Shahar G, Herishanu-Gilutz S, Holcberg G, Kofman O. In first-time mothers, post-partum depressive symptom prospectively predict symptoms of post-traumatic stress. J Affect Disord 2015;186:168-70. https://doi.org/10.1016/j.jad.2015.07.021.

[5] Newbrander W, Natiq K, Shahim S, Hamid N, Skena NB. Barriers to appropriate care for mothers and infants during the perinatal period in rural Afghanistan: A qualitative assessment. Glob Public Health 2014;9:37-41. https://doi.org/10.1080/17441692.2013.827735.

[6] Dennis CL, Brown HK, Brennenstuhl S. The Postpartum Partner Support Scale: Development, psychometric assessment, and predictive validity in a Canadian prospective cohort. Midwifery 2017;54:18-24. https://doi.org/10.1016/j.midw.2017.07.018

[7] Setyowati S. An Ethnography Study of Nutritional Conditions of Pregnant Women in Banten Indonesia. Makara J Heal Res 2011;14:5- 10 . https://doi.org/10.7454/msk.v14i1.640.

[8] Prayono, Kurniarum A. Consumption of Herbal Medicine Consumption to Maintain a Healty Body during Pregnancy and After Childbrith in the Kajora Village, South Klaten. Intergrated J Heal Sci 2014;3 (1), 64-.

[9] Kiani S, Rich K, Herkert D, Safron C. Delivery Mode and Feedback Outcomes Among New Mothers in Nicaragua. Matern Child Nutr 2018;14 (1), 1-

[10] Seifi M, Abbasalizadeh S, Mohammad-AlizadehCharandabi S, Khodaie L, Mirghafourvand M. The effect of Rosa (L. Rosa canina) on the incidence of urinary tract infection in the puerperium: A randomized placebocontrolled trial. Phyther Res 2018;32:76-83. https://doi.org/10.1002/ptr.5950.

[11] LS S, Husaini, Ilmi B. Study of Culture and Symbolic Meaning of the Behavior of Pregnant Woman and Postpartum Mothers. Peridoical J Heal 2017;1 (2), 78-.

[12] Abdullah SZS, Nilan P, Germov J. Postpartum dietary restrictions and taboos among indigenous Temiar women in Peninsular Malaysia: A qualitative study. Malays J Nutr 2016;22:207-18.

[13] Y R. Postpartum Culture of the Indonesian Community: Should It Be Maintained? 2018;6 (1), 1-3.

[14] Cwikel J, Segal-Engelchin D, Niego L. Addressing the needs of new mothers in a multi-cultural setting: An evaluation of home visiting support for new mothers Mom to mom (Negev). Psychol Heal Med 2018;23:51724. https://doi.org/10.1080/13548506.2017.1363896.

[15] Muzik M, Kirk R, Alfafara E, Jonika J, Waddell R. Teenage mothers of black and minority ethnic origin want access to a range of mental and physical health support: A participatory research approach. Heal Expect 2016;19:403-15. https://doi.org/10.1111/hex.12364.

[16] Chapman DJ, Pérez-Escamilla R. Acculturative type is associated with breastfeeding duration among low-income Latinas. Matern Child Nutr 2013;9:188-98. https://doi.org/10.1111/j.1740- 8709.2011.00344.x.

[17] Daise TA, Kabir N, Yesmin N, Tasnim S, Ahasan AB. Psychiatric disorders in puerperium. Bangladesh J Obstet Gynecol 2013;28:38https://doi.org/10.3329/bjog.v28i1.30083.

[18] Zhang YP, Zhang LL, Wei HH, Zhang Y, Zhang CL, Porr C. Post partum depression and the psychosocial predictors in first-time fathers from northwestern China. Midwifery 2016;35:47-52. 
https://doi.org/10.1016/j.midw.2016.01.005.

[19] Gao L ling, Sun K, Chan SW chi. Social support and parenting self- efficacy among Chinese women in the perinatal period. Midwifery 2014;30:532-8. https://doi.org/10.1016/j.midw.2013.06.007.

[20] Setiawati N, Setyowati, Budiati T. SETIA Health Education Set Enhances Knowledge, Attitude, and Parenting Self-Efficacy Score in Postpartum Adolescent Mothers. Compr Child Adolesc

Nurs2017;40:114-27.

https://doi.org/10.1080/24694193.2017.1386979.

[21] Sofolahan-Oladeinde YA, Iwelunmor JI, Conserve DF, Gbadegesin A, Airhihenbuwa CO. Role of healthcare in childbearing decision- making of WLHA in Nigeria: Application of PEN-3 cultural model. GlobPublic Health 2017;12:680-93.

https://doi.org/10.1080/17441692.2016.1221982. 